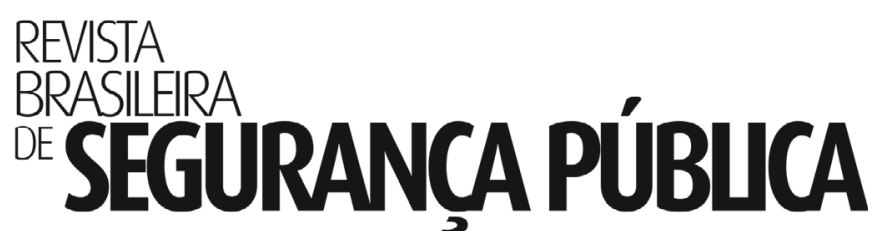

\author{
Volume 12 \\ Número 2 \\ Agosto/Setembro de 2018
}

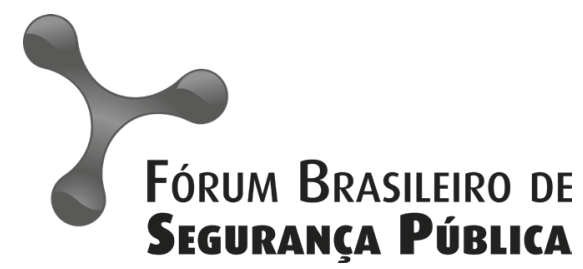

ISSN 1981-1659 


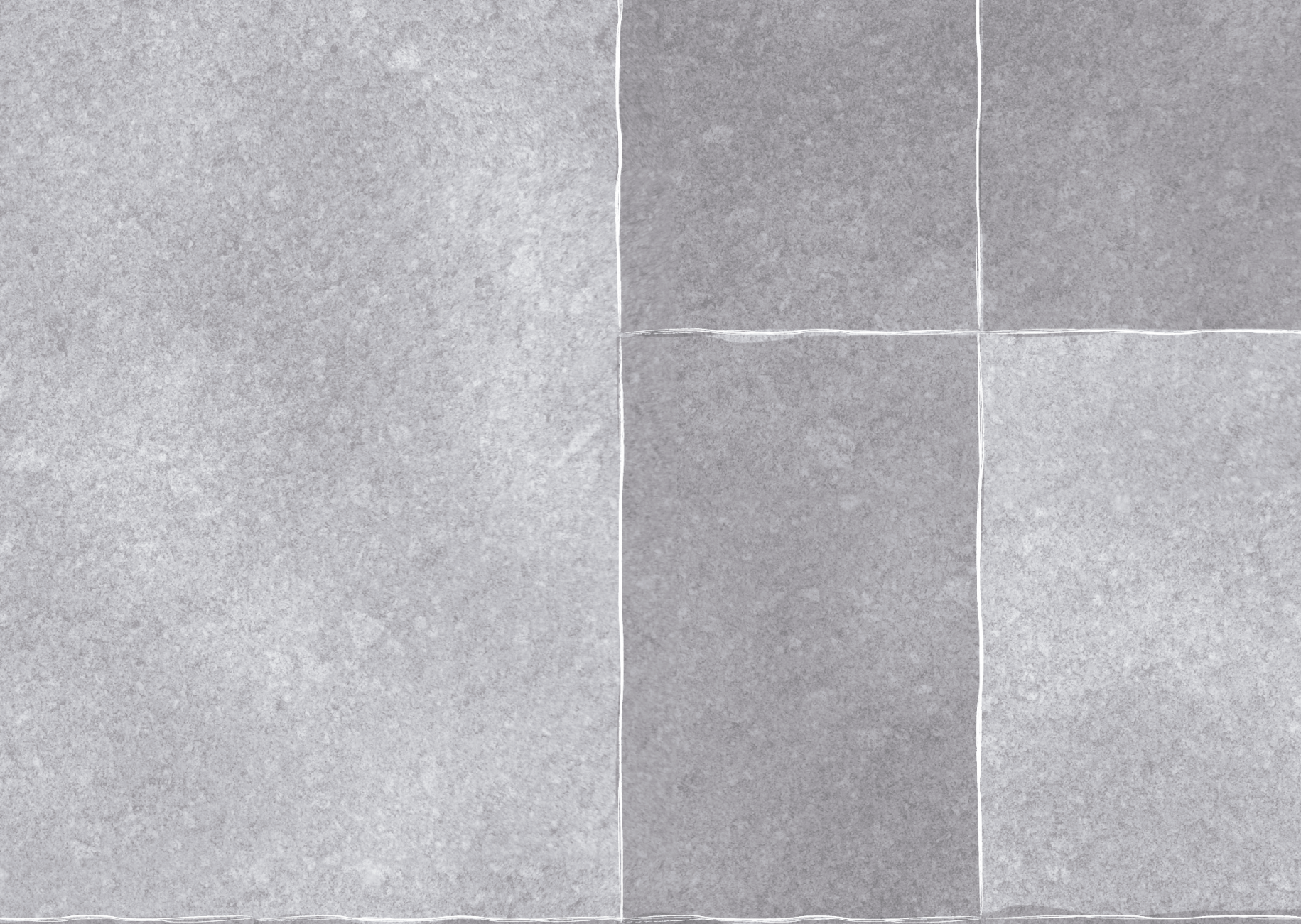




\section{A Violência na Análise do Contexto das Escolas Públicas: Evidências da Rede Estadual de Ensino de Minas Gerais}

\section{André Augusto Anjos Couto}

Doutorando em Educação pela Universidade de São Paulo (USP), Mestre em Educação pela Universidade Federal de Minas Gerais (UFMG). Professor de educação básica do Rede Estadual de Minas Gerais.

\section{José Francisco Soares}

Data de recebimento: $17 / 06 / 2018$

Data de aprovação: 16/10/2018

DOI: 10.31060/rbsp.2018.v12.n2.954

\begin{abstract}
Resumo
A violêncio é um fenômeno presente na realidade escolar brasileira e por isso deve ser considerada nas análises contextuais das escolas. o objetivo desse artigo é analisar a associação entre violêncio no entorno das escolas e o contexto escolar. Uma contribuição específica deste artigo é sintetizar dados de boletins de ocorrêncio de eventos ocorridos no entorno das escolas. São utilizados dados de 18.542 pessoas registradas em boletins de ocorrência gerados no entorno das escolas estaduais de Minas Gerais e de 3.655 escolas dessa rede. Os boletins de ocorrêncio fornecem informações sobre o tipo de crime, tipo de envolvimento (outor, cooutor, suspeito e vitima), sexo, cor e faixa etário dos envolvidos nessos ocorrências. o contexto escolar foi descrito através dos indicadores de nível socioeconômico das escolas, regularidade e formação docente, complexidade da gestõo e infraestrutura das escolas, criados pelo INEP. Foram realizados procedimentos descritivos e de associação. Os resultados demonstraram que pessoas pardas são as mais envolvidas nas ocorrências e as mulheres corresponderam ao maior número de vítimas. Observou-se uma prevalêncio maior no participação dos crimes de pessoas entre 11 e 17 onos. Evidenciou-se tombém que o entorno das escolos com olto rotatividade, menor nível socioeconômico, baixa complexidade e pouco infroestrutura tem mais registros de ocorrêncios.
\end{abstract}

\section{Palavras -Chave}

Violência; Violência Escolar; Contexto Escolar. 


\section{Abstract \\ Violence in the analysis of the context of public schools: Evidence from the State Education System of Minas \\ Gerais}

Violence is a phenomenon present in Brazilian school reality and for this it must be considered in the contextual analyzes of schools. The purpose of this article is to analyze the association between violence in schools and the school context. A specific contribution of this paper is to synthesize dato from police records of events occurring around schools. Were used dato from 18,542 people listed in police reports of violent incidents that happened near any of the 3,655 state schools in Minas Gerais. These records provided information about the type of crime, type of involvement (outhor, co-outhor, suspect and victim), gender, color, and age group of the involved. The school context was described through the indicators of Socioeconomic Status of schools, Regularity and Teacher Training, Complexity of Management and Infrastructure of schools, created by INEP. Descriptive and association procedures were performed. Results showed a greater involvement of brown people as authors in crimes and women corresponding to a higher number of victims. There was also a greater prevalence in the participation of crimes for teenagers of age among 11 and 17 years old. There is evidence that schools of high turnover, lower socioeconomic status, lower complexity of schools and little infrastructure were more associated with cases of violence around them.

\section{Keywords}

Violence; school violence; school context. 


\section{INTRODUÇÃO}

om o objetivo de contribuir com a introduçáo de políticas que possibilitem a melhoria da qualidade educacional, pesquisas tem se dedicado a analisar quais fatores influenciam a aprendizagem dos alunos. Alguns trabalhos abordam a perspectiva de fatores intraescolares, tais como aspectos pedagógicos e enturmações, outros os fatores extraescolares, tais como a relaçáo família/escola, a influência da violência e do bairro na aprendizagem dos estudantes (FRANCO et al., 2007; ALMEIDA; BETINI, 2015).

Estudos realizados com dados estatísticos coletados no Brasil tem contribuído para o conhecimento da dinâmica escolar no país, muitos dos quais tem demonstrado que a qualidade da educaçáo, entendida como maior desempenho dos estudantes em testes, está associada a estabelecimentos que congregam alunos com melhores condiçôes socioeconômicas e escolas com melhor infraestrutura, esses trabalhos se caracterizaram por se concentrarem no estudo do contexto escolar ${ }^{1}$ (KARINO; LAROS, 2017).
Embora as pesquisas com foco na análise contextual escolar brasileira apresentem literatura consolidada, há uma lacuna nessa linha de pesquisa ao não considerar um fator crescente no debate educacional que é a presença da violência nesse contexto. É neste ponto que este artigo contribui ao analisar a associação da violência no entorno das escolas com o contexto escolar.

A relação entre violência e escola é um tema frequente nos debates educacionais, políticos e midiáticos em decorrência da multiplicaçáo dos episódios violentos que envolvem a comunidade escolar e que interferem no processo educativo dos estudantes (RUOTTI, 2010).

O crescimento dos eventos violentos envolvendo as escolas tem suscitado o desenvolvimento de pesquisas com o objetivo de compreender como as composiçóes de gênero e raça, a exclusão social, a influência da comunidade e o entorno das instituiçóes se relacionam com a violência e a formação dos alunos. Podem ser destacados os trabalhos de Sposito (2001), Zaluar e Leal (2001), Abramovay e Rua (2002), Grogger (1997), Bowen e Bowen (1999), 
Ammermüller (2007), Silva e Salles (2010), Ribeiro (2013), Waiselfisz (2015), Cerqueira et al. (2016) dentre outros.

Este artigo relata pesquisa que pode ser caracterizada como estudo da community violence, termo que designa a violência de uma forma geral que acontece no entorno das escolas e acomete as pessoas da comunidade escolar (GAMA; SCORZAFAVE, 2013). O entorno das escolas pode ser definido como o contexto socioespacial, socioeconômico e cultural que abrange, além dos alunos e suas famílias, demais pessoas que ali residem, trabalham e convivem (ALMEIDA; BETINI, 2015).

Debarbieux (1998) indica que os estudos sobre violência deveriam abranger três campos a saber: os crimes e delitos previstos pelo código penal, as incivilidades (palavras e expressões ofensivas) e o sentimento de insegurança em relação à violência. Este estudo tem foco nos delitos previstos pelo código penal utilizando como referências empíricas os dados dos boletins de ocorrência (B.O) dos órgãos de segurança de Minas Gerais (Polícias Militar, Civil e Secretaria de Defesa Social) e indicadores escolares desenvolvidos pelo Instituto $\mathrm{Na}$ cional de Pesquisas e Estudos Educacionais Anísio Teixeira (INEP). A utilização desse tipo de informação é percebida com menor frequência em trabalhos brasileiros com essa temática devido à grande dificuldade de operacionalizaçáo dos bancos de dados relacionados aos boletins e sua pouca ligaçáo com as bases de dados educacionais existentes. Destaca-se que este artigo procura contribuir com as discussóes na área ao ampliar os tipos de ocorrências analisados e não necessariamente trabalhar com dados oficiais de relatórios sobre cri- minalidade.

O artigo está estruturado em cinco seções além desta introdução. A primeira é dedicada à revisáo de literatura sobre o tema, a segunda à metodologia e dados utilizados, a terceira aos resultados, a quarta à discussáo do artigo e a última à conclusão.

\section{Revisão de literatura}

Uma tendência observada em diversos trabalhos que abordam a community violence é a análise do desempenho acadêmico dos alunos a partir da exposição destes a ambientes violentos. Bowen e Bowen (1999), analisando alunos de ensino fundamental e médio nos Estados Unidos, demonstraram que homens afro-americanos estavam mais expostos à violência no entorno das escolas e que residir ou frequentar uma vizinhança perigosa impacta de forma negativa o seu desempenho escolar.

Grogger (1997), ao analisar a exposição à violência por parte dos estudantes de ensino médio, suas características demográficas e o local em que a escola estava inserida, demonstrou que a exposiçáo a níveis moderados de violência diminuía em $5,1 \%$ as chances dos alunos norte-americanos concluírem essa etapa escolar.

Hurt et al. (2001), Ratner et al. (2006), Borofsky et al. (2013) apontaram que maior exposição dos estudantes a atos de violência estava relacionado à médias de desempenho menores, mais dias de faltas escolares e a problemas na escola, demonstraram também que o sentimento de segurança estava relacionado a melhores desempenhos em tarefas escolares. 
Akiba, Le Trende e Baker (2002) demonstraram que em países cuja a desigualdade educacional é grande há uma associação significativa com o nível de violência envolvendo as escolas. Severnini e Firpo (2009) utilizando dados do Sistema de Avaliação da Educação Básica (SAEB) encontraram resultados semelhantes identificando que o ambiente violento nas escolas estava mais associado às unidades que apresentavam os menores resultados.

Becker e Kassouf (2016) demonstraram que a possibilidade de observar agressóes entre alunos é maior em ambientes escolares onde ocorreram crimes contra patrimônio, contra a pessoa, tráfico de drogas ou atuação de gangues. Gama e Scorzafave (2013) demonstraram que estudantes de escolas inseridas em regióes mais violentas apresentavam menor desempenho em Matemática e Leitura.

Os resultados da pesquisa de Ribeiro (2013), ao analisar a implantaçáo das Unidades de Polícia Pacificadora (UPPs) no Rio de Janeiro e sua relaçáo com a movimentação docente, apontaram que a rotatividade de professores é mais alta em áreas que receberam UPPs e o fato de uma escola estar localizada em favelas reduz sua capacidade de atrair professores.

Teixeira e Kassouf (2015) e Tavares e Pietrobom (2016) utilizando dados do Sistema de Avaliação de Rendimento Escolar do Estado de Sáo Paulo (SARESP) demonstraram que um aluno do mesmo sexo, mesma cor/raça que pertença a nível socioeconômico similar pode apresentar rendimento menor se estiver matriculado em uma escola que apresente mais violência, demonstraram também que os crimes contra o patrimônio estáo relacionados com a dificuldade da gestáo escolar e com as condiçóes socioeconômicas do entorno das unidades.

Tavares e Pietrobom (2016) observaram também que maior qualificação dos docentes não se traduzia em maior habilidade no controle do comportamento dos alunos, além de encontrarem uma relação positiva entre qualificaçáo de professores e ocorrências de atos violentos tais como agressóes e ameaças. Para estes autores, os docentes com menor formação (por exemplo magistério) teriam em média mais habilidade no trato com questóes de violência se comparados a docentes com melhor formação.

Cerqueira et al. (2016) ao analisar as condiçóes educacionais em 81 municípios que fazem parte do Pacto Nacional para Redução de Homicídios (PNRH) identificou que uma maior rotatividade docente, menor nível socioeconômico e maior complexidade das escolas estava correlacionado positivamente com maior número de homicídios.

\section{Metodologia}

Este trabalho tem como objetivo central analisar a associação entre a violência no entorno das escolas e o contexto escolar expresso nas características das unidades. Os dados analisados neste estudo, entretanto, não permitem estabelecer relações de causalidade entre as características contextuais e os crimes no entorno das escolas. O outro objetivo deste artigo é traçar um perfil dos envolvidos a partir das informaçóes sobre as características sociodemográficas que constam nos boletins de ocorrência. 
Como hipótese central espera-se que as escolas cujo entorno é mais violento apresentem condições contextuais mais difíceis como alta rotatividade de professores, baixo nível socioeconômico (NSE), infraestrutura mais comprometida, maior complexidade e menor número de docentes com formação adequada.

Os dados relacionados à violência são provenientes dos boletins de ocorrência gerados pelos órgáos de segurança de Minas Gerais e sua utilizaçáo constitui uma nova oportunidade para a compreensão desse fenômeno, essa é a principal contribuição deste artigo. Os dados que informam sobre o contexto se referem aos indicadores educacionais construídos pelo INEP. Optou-se pela utilização desses indicadores pelo fato dos mesmos conseguirem expressar as características contextuais das escolas de educação básica². O foco desse estudo são 3.655 escolas estaduais de Minas Gerais e o ano de referência dos dados é 2015. Para as análises serão utilizadas técnicas descritivas e de associação entre variáveis através da regressão logística.

\section{Dados}

As informações constantes nos boletins de ocorrência não permitem especificar se os atos violentos são praticados por alunos ou contra pessoas que trabalham nas escolas. Apesar desta limitaçáo, os dados considerados neste estudo, pela sua amplitude e origem, permitem verificar a exposição dos jovens em idade escolar a ambientes violentos, o que pode levar a prejuízos a sua formação acadêmica e humana.

Os dados referentes à violência são provenientes do sistema de Registros de Eventos de Defesa Social (REDS) da Secretaria de Segurança Pública de Minas Gerais (SESP-MG), sendo considerados para este estudo apenas os registros de ocorrências cujo "local imediato do fato" 3 era uma instituição de ensino pública estadual de Minas Gerais.

O banco de registros da SESP-MG não determina em qual escola estadual a ocorrência foi gerada e somente apresenta como localizadores o município, o endereço e as coordenadas geográficas do fato. Assim sendo o primeiro passo foi relacionar cada registro com o código de cada escola estadual. A primeira etapa deste trabalho consistiu em cruzar os dados relacionados às coordenadas geográficas das ocorrências e das escolas ${ }^{4}$. Na segunda foram cruzados os dados relativos aos endereços das ocorrências com os endereços das escolas declaradas no Censo Escolar e a terceira etapa consistiu em identificar, manualmente, o local descrito nas ocorrências e sua proximidade com as escolas estaduais através de fotos de satélite utilizando para isso os aplicativos "Google Maps" e "Google Earth".

A informação preenchida pelo agente público que redigiu a ocorrência tem li-

2 o INEP desenvolveu a partir de informações do Censo Escolar um conjunto de indicadores educacionais que permitiram melhor caracterização das escolos brosileiras. Estes indicadores expressam informações sobre a mobilidade e formação docente além da complexidade e nível socioeconômico das escolas.

3 Embora no banco REDS esses registros tenham sido atribuídos pelos agentes públicos como o local do fato as escolas estaduais estes dados abrangem ocorrências geradas tonto no entorno quanto dentro dessas instituiç̄ões. 
mitaçóes. Em muitos registros apareceram regionalismos tais como "rua da matriz", logradouros que trocaram de denominação ou falta do endereço sendo designado somente o bairro. Outro tipo de inconsistência encontrada foi o registro equivocado apontando escolas municipais e privadas como estaduais.

Após este minucioso trabalho foram identificados um total de 10.409 registros de boletins de ocorrências. Como cada boletim pode abranger mais de uma pessoa, ao final foram identificados 18.542 registros de pessoas envolvidas em ocorrências relacionadas às escolas estaduais. Desse total, 16.484 foram relacionados de forma precisa a uma unidade de ensino estadual de Minas Gerais, os outros 2.058 não foi possível obter precisão, entretanto como no REDS eles foram referenciados pelo agente público como "local imediato do fato" em escolas estaduais eles não foram excluídos das análises. Ao final foram identificados 105 tipos diferentes de crimes em que estavam envolvidas as 18.542 pessoas.

Devido à grande variedade de crimes, optou-se por categorizar os boletins permitindo melhor compreensáo dos dados, para isso os crimes foram classificados em cinco categorias definidas a partir das penas previstas nas legislaçóes pertinentes ${ }^{5}$. A categoria "leve" abrange crimes em que as penas variam de 15 dias a 1 ano, a "média" abrange crimes em que as penas iniciam com 1 ano e variam até 5 anos dependendo do agravante no crime, a "grave" pos- sui crimes com penas iniciadas a partir de 2 anos e variando até 8 anos, a categoria "gravíssima" abrange crimes com penas iniciando a partir de 4 anos e variando até 20 anos. A categoria "outras ocorrências" envolve situaçóes relacionadas à localização de veículos roubados nas adjacências das escolas, denúncias realizadas a partir de telefones localizados nas imediaçōes das instituiçóes e açóes preventivas dos setores de segurança contra a violência. Foi possível também através desse banco de dados classificar os envolvidos por sexo, cor/raça, faixa etária e tipo de envolvimento com o crime.

Para caracterização do contexto escolar foram utilizados como referência cinco indicadores educacionais ${ }^{6}$. O nível socioeconômico (NSE) das unidades escolares é um indicador na escala 0 a 10 que capta as condiçóes de seus alunos através de dados obtidos nos questionários contextuais das avaliaçóes externas tais como o SAEB. Valores mais próximos de 10 indicam que os estudantes das escolas possuem condição social mais privilegiada.

A regularidade dos docentes é um indicador que capta o nível de rotatividade dos professores de uma escola, ou seja, quanto mais regular é um quadro de docentes mais estável é a presença do professor na escola. Para manter a mesma interpretaçáo as escolas foram posicionadas em uma escala de 0 a 10 sendo que mais próximo de 10 maior é a sua regularidade.

5 Decreto-Lei 2.848, de 07 de dezembro de 1940, Decreto-Lei 3.688, de 03 de outubro de 1941, Lei 6.538 de 22 de junho de 1978, Lei 7.716, de 05 de janeiro de 1989, Lei 8.069, de 13 de julho de 1990, Lei 9.455, de 07 de abril de 1997, Lei 10.826, de 22 de dezembro de 2003, Lei 11.343, de 23 de ogosto de 2006. 
O indicador de formaçáo do docente sintetiza a adequaçáo da formação dos docentes para o exercício do ensino. Neste trabalho foi considerado como referência os dados sobre os professores que são formados na disciplina que lecionam, portanto com formaçáo adequada.

A infraestrutura das escolas é um indicador construído a partir de informaçóes obtidas no Censo Escolar que consideram os equipamentos e estruturas das escolas brasileiras. Assim como no NSE e na regularidade as escolas são posicionadas em uma escala de 0 a 10 sendo que valor mais próximo de 10 representa melhor infraestrutura escolar (SOARES NETO et al., 2013).

O indicador de complexidade da gestáo das escolas é uma síntese de características que tornam a gestão da escola mais desafiadora como o número de matrículas, turnos e etapas. Esse indicador na forma que é divulgado pelo INEP possui seis categorias de graduaçáo. Para uso neste estudo esta variável foi dicotomizada tomando-se como "alta complexidade" as escolas que estavam localizadas nos níveis cinco e seis do indicador.

Como a violência no entorno das escolas foi captada a partir dos boletins de ocorrência estes dados se encontravam de modo desagregado a nível dos indivíduos. Sendo assim, foi necessária uma agregação ao nível da escola de modo a representar o número de crimes que aconteceram no entorno ou dentro de cada instituição. Como os dados das ocorrências abrangem todo o estado de Minas Gerais foram consideradas no estudo todas as 3.655 escolas públicas estaduais sendo que em $2.314(63,3 \%)$ foram encontrados registros de crimes no seu entorno. A variável que representa a violência no entorno das escolas foi dicotomizada em duas categorias, presença de crimes e ausência de crimes. Devido à grande variedade nos tipos de crimes os dados sobre essa informação foram agregados em modos de contagem refletindo o número de crimes que ocorreu no entorno de cada escola. A categoria presença de crimes abrange todas as escolas que apresentaram crimes em seu entorno e a categoria ausência de crimes as escolas que não apresentaram essas ocorrências. Foram considerados todos os tipos de crime registrados nos boletins de ocorrência para a criaçáo dessa variável.

O modelo estatístico definido para verificar a associaçáo entre a violência e o contexto escolar será a regressáo logística binária. Esse modelo é indicado quando a variável resposta ou central na análise assume uma distribuiçáo dicotômica, ou seja, com a possibilidade de apenas dois valores aqui no caso presença ou ausência de crimes (DEMARIS, 1995). Para a inclusão no modelo, as variáveis contextuais das escolas NSE, regularidade, formação dos docentes e infraestrutura foram dicotomizadas a partir da sua mediana ${ }^{7}$.

\section{Resultados}

Primeiro serão apresentados os resultados descritivos com foco nas características sociodemográficas obtidas nos dados do REDS e em seguida serão apresentados os resultados da regressão com foco na análise do contexto escolar. 
Dados do REDS (2015) apontam que no entorno das escolas estaduais de Minas Gerais $66,0 \%$ dos crimes cometidos foram de categoria leve abrangendo situaçóes do tipo ameaça, arremesso de projétil contra transporte público, atritos verbais, vias de fato, danos ao patrimônio, constrangimento, pichaçóes e consumo de drogas.

Os crimes graves corresponderam a $14,7 \%$ do total sendo caracterizados por furto, sequestro de crianças, posse e porte ilegal de armas, falsificação de documentos, disparo de arma de fogo, corrupção de menores e abusos de incapazes (REDS, 2015).

Os crimes de gravidade média corresponderam a $9,0 \%$ do total, abrangendo situaçôes de desacato a funcionários públicos, receptaçáo de artefatos produtos de crimes, apropriação indébita, injúrias raciais e sexuais, assédio sexual, calúnia e estelionato (REDS, 2015).

Os crimes gravíssimos com maior potencial contra a vida das pessoas corresponderam a $1,9 \%$ abrangendo estupros, estupros de vulneráveis, extorsão, roubo, homicídio e tráfico de drogas (REDS, 2015).

Ao lavrarem as ocorrências os órgãos de segurança identificam os indivíduos e os classificam quanto ao tipo de envolvimento com o crime. Os envolvidos podem ser classificados como autores que são os praticantes do crime, se houver mais de um autor os outros são classificados como coautores, os suspeitos que são as pessoas que apresentaram indícios de estarem participando do ato criminoso e a vítima é a pessoa que foi o alvo do crime.
A atribuiçáo da autoria do crime é realizada pelo agente público, majoritariamente o policial militar, no ato do preenchimento da ocorrência. Portanto, essa informaçáo é limitada por fatores como a interpretaçáo desse agente, a açáo dos envolvidos no fato e a limitaçáo de informaçóes detalhadas acerca do evento, principalmente quando náo há flagrante ou testemunhas. Isso ocorre porque as ocorrências não refletem o resultado de investigaçóes encaminhadas por outras instituições do sistema de justiça criminal em fases posteriores do processo quando necessárias.

Uma outra limitação que precisa ser considerada é o fato de existirem ocorrências em que não há vítimas, tais como em crimes contra o patrimônio público (por exemplo depredação de prédio escolar). A hipótese nesse caso converge para o fato da pessoa responsável que acionou os órgãos de segurança (diretor, coordenador) ser eventualmente atribuída à condição de vítima por ser a pessoa referência desse órgão.

Dados do REDS (2015) apontam que dos 18.542 indivíduos envolvidos nos crimes no entorno das escolas estaduais $48,4 \%$ foram autores, $0,5 \%$ coautores, $2,6 \%$ suspeitos e $48,5 \%$ vítimas. Considerando o gênero dos envolvidos $54 \%$ pertencem ao sexo masculino, $45,0 \%$ ao feminino e 1,0\% náo apresentaram informação.

Considerando somente os autores, $69,0 \%$ são do sexo masculino e $31 \%$ do sexo feminino. $\mathrm{Na}$ categoria de vítimas, $61,0 \%$ são do sexo feminino, $37,0 \%$ do sexo masculino e 2,2\% não apresentaram informação (REDS, 2015). Esses 
resultados demonstram que o percentual de vítimas do sexo feminino em crimes no entorno das escolas é $24,0 \%$ maior se comparado com as do sexo masculino e entre a autoria dos crimes os homens correspondem a $38,0 \%$ a mais se comparado com as mulheres.

Os dados do REDS (2015) demonstram também que as pessoas do sexo masculino foram mais acometidas no entorno das escolas estaduais por roubo $(62,5 \%)$, estupro de vulnerável $(15,0 \%)$ e homicídio (12,5\%). Entre as mulheres, os crimes das quais foram mais vítimas correspondem a ameaças $(24,9 \%)$, furtos $(22,9 \%)$ e vias de fato $(19,0 \%)$.
A tabela 1 apresenta a distribuição das pessoas por tipo de envolvimento com o crime segundo a sua cor/raça. Os resultados apontam que os pardos participaram $25,5 \%$ a mais como autores dos crimes que os brancos e $32,2 \%$ a mais do que os pretos. Entre as vítimas os pardos também foram maioria correspondendo a $43,4 \%$ do total, esse número é $4,5 \%$ superior aos brancos e 35,5\% superior aos pretos. Esses números demonstram que as pessoas pardas correspondem aos maiores envolvidos nas ocorrências e se considerarmos somente os negros (pardos e pretos) o percentual como autores dos crimes aumenta para 64,6\% e entre as vítimas 51,3\%.

\section{Tabela 1 - Distribuição percentual dos envolvidos nos crimes no entorno das escolas segundo a cor/raça}

\begin{tabular}{l|r|r|r|c}
\multicolumn{1}{c|}{ Cor } & Autor & Coautor & Suspeito & Vítima \\
\hline Brancos & 22,9 & 26,6 & 18,6 & 38,9 \\
\hline Pardos & 48,4 & 43 & 46,7 & 43,4 \\
\hline Pretos & 16,2 & 17,7 & 14,3 & 7,9 \\
\hline Amarelos & 0,2 & 0 & 0,5 & 0,5 \\
\hline Sem Informação & 12,3 & 12,7 & 19,9 & 9,3 \\
\hline Total & 100 & 100 & 100 & 100
\end{tabular}

Fonte: REDS, 2015

Entre as vítimas do sexo feminino, as mulheres pardas correspondem a 43,6 $\%$, as brancas a $41,5 \%$, as pretas a $7,3 \%$, amarelas a $0,5 \%$ e $7,1 \%$ não apresentaram informação sobre cor/raça. Se considerarmos as mulheres negras (pardas e pretas), o percentual de vítimas sobe para $50,9 \%$, uma diferença de $9,4 \%$ a mais se comparado com as mulheres brancas (REDS, 2015).

A faixa etária é uma característica relevante quando se discutem aspectos escolares. Dados do REDS (2015) apontam que o percentual de envolvidos até 10 anos corresponde a 2,6\% do total, entre $11 \mathrm{e}$ 14 anos corresponde a 30,4\%, entre 15 e 17 anos a $33,4 \%$, entre 18 e 24 anos equivale a $7,5 \%$ e acima de 25 anos a $24,9 \%$. Um percentual de 1,2\% dos envolvidos não apresentaram informação sobre idade.

Esses dados sobre faixa etária demonstram que 63,8\% dos envolvidos em casos de violência no entorno das escolas estão na fase da adolescência, período fundamental na definição do futuro e na formação da pessoa como cidadão. Esse percen- 
tual aponta para o náo cumprimento do Art. 227 da Constituiçáo Nacional, que apresenta como deveres da Sociedade, Família e Estado a garantia ao adolescente das condiçóes adequadas para se viver, evitando toda e qualquer forma de negligência, discriminação, exploração, violência, crueldade e opressão (BRASIL, 1988).

\section{Associação entre violência no entorno das escolas e contexto escolar}

Um modelo de regressão logística foi utilizado para verificar a associação entre a presença de violência no entorno das escolas com o contexto escolar. É relevante salientar que em pesquisas na área de educação, que utilizam dados provenientes de registros administrativos, podem existir problemas de endogeneidade entre as variáveis explicativas. Essa é uma limitação que não deve, entretanto, impedir a análise deste tipo de dado, frequentemente os únicos disponíveis. A tabela 2 apresenta as estatísticas descritivas e o quadro 1 a distribuição das variáveis inseridas no modelo de regressão.

\begin{tabular}{|c|c|c|}
\hline Variáveis & Estatísticas descritivas & Desvio Padrão \\
\hline $\begin{array}{l}\text { Presença de crimes* } \\
\text { (variável resposta) }\end{array}$ & 2.314 & -- \\
\hline NSE (média) & 4,8 & 0,49 \\
\hline $\begin{array}{l}\text { Regularidade dos } \\
\text { Docentes (média) }\end{array}$ & 6,43 & 0,93 \\
\hline $\begin{array}{l}\text { Formação dos } \\
\text { Docentes }\end{array}$ & 68,2 & 15,5 \\
\hline $\begin{array}{l}\text { Infraestrutura das } \\
\text { Escolas (média) }\end{array}$ & 5,98 & 0,47 \\
\hline Baixa Complexidade* & 1.180 & -- \\
\hline \multicolumn{2}{|c|}{$\begin{array}{l}\text { "Número de escolas } \\
\text { "Percentual de docentes com formacõo adequado }\end{array}$} & Fonte: elaboraçõo própria. \\
\hline
\end{tabular}

Quadro 1 - Distribuição das variáveis utilizadas na regressão

\begin{tabular}{l|l} 
Variável & Descrição \\
\hline Presença de crimes (Variável Resposta) & Escolas com presença de crimes no entorno $=1$ \\
\hline Baixa Regularidade & Escolas com quadro de professores com baixa regularidade $=1$ \\
\hline Baixo NSE & Escolas com baixo nível socioeconômico $=1$ \\
\hline Baixa Formação & $\begin{array}{l}\text { Escolas com menor percentual de docentes com curso superior na disciplina } \\
\text { que lecionam }=1\end{array}$ \\
\hline Baixa Infraestrutura & Escolas com baixa infraestrutura $=1$ \\
\hline Baixa Complexidade & Escolas com baixa complexidade $=\mathbf{1}$
\end{tabular}


O modelo logístico binário utilizado é definido pela seguinte equação:

$$
\operatorname{logit}(Y i=1)=\ln \left\lfloor\frac{P(Y i=1)}{1-P(Y i=1)}\right\rfloor
$$

Logit $\left(Y_{i}=1\right)=\beta 0+\beta 1$. Baixo NSE $+\beta 2$. Baixa Regularidade + 33. Baixa Formação $+\beta 4$. Baixa Complexidade $+\beta 5$. Baixa

Infraestrutura
As estimativas dos parâmetros obtidas com o uso do software SPSS estão apresentadas na tabela 3. A interpretação relevante para a questão de pesquisa deste artigo é obtida nas razóes de chance de o evento ocorrer. Valores acima de 1 indicam maior chance de ocorrerem crimes no entorno das escolas.

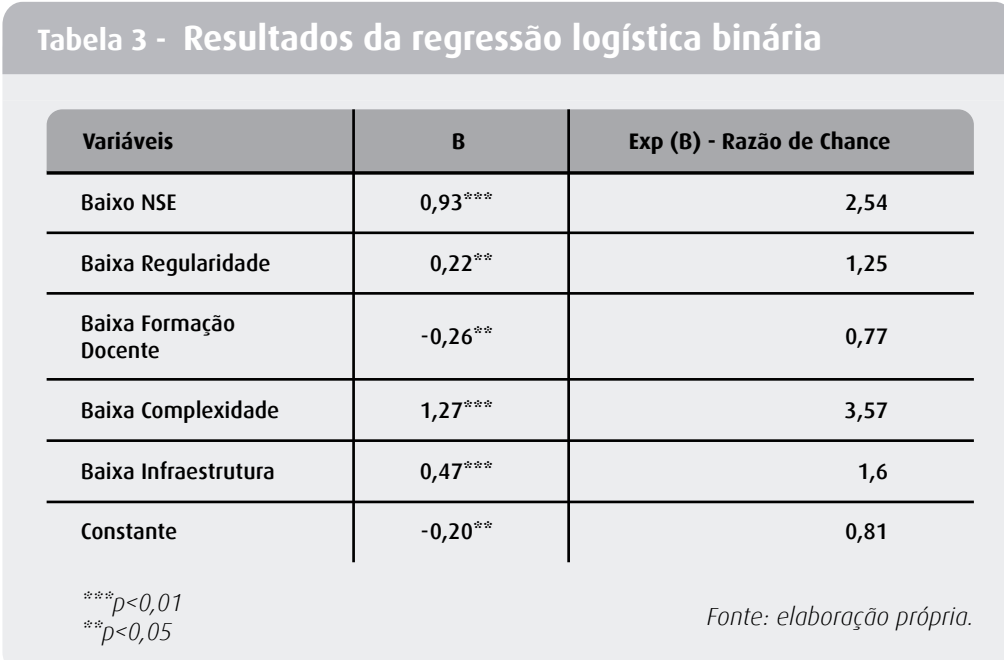

Os resultados apontam que a violência no entorno das escolas está associada às unidades de ensino que apresentam piores condiçóes de funcionamento. De fato, em unidades escolares com menor NSE, a chance de ocorrer crimes em seu entorno é maior $(2,54)$ se comparada com as escolas que atendem alunos com melhores condições socioeconômicas.

No que diz respeito à regularidade, os resultados demonstram que a chance de ocorrer crimes no entorno das escolas com baixa regularidade dos docentes é maior $(1,25)$ se comparada com escolas que possuem o quadro de professores mais regular e estável.

Os resultados apontam ainda que a chance de ocorrer crimes no entorno é maior em escolas com menor grau de complexidade $(3,57)$ se comparadas com escolas mais complexas e com relaçáo à infraestrutura os resultados demonstram que em escolas menos equipadas, com estrutura física inferior, é maior a chance de crimes em seu entorno $(1,60)$ se comparado com unidades de infraestrutura superior.

O sinal do coeficiente associado à formaçáo docente apresentou-se negativo, contrário ao esperado $(-0,26)$ apontando que a violência representada pela presença de crimes no entorno da escola está negativamente associada à baixa formaçáo do corpo docente. Ou seja, em unidades que possuem o quadro de professores, em sua grande maioria, sem formação adequa- 
da na disciplina que lecionam, menor é a chance de ocorrer crimes em seu entorno $(0,77)$ se comparado às unidades que possuem um grupo maior de docentes com formação adequada.

\section{Discussão}

O maior percentual de crimes identificados no entorno das escolas consiste em atritos verbais e corporais, ameaças, pichaçóes e danos ao patrimônio. Uma explicação para esse perfil de crimes está relacionada ao fato de o ambiente analisado ser o entorno de uma escola e desse modo, ser frequentado em sua grande maioria, por indivíduos que ligados ao ambiente escolar. É esperado que confusōes, brigas e ameaças que se iniciem dentro da escola extrapolem para o espaço extraescolar.

O chamado efeito concentração também auxilia na compreensão desse perfil de crimes, ou seja, a escola é uma instituição que geograficamente concentra um grande número de alunos e proporciona a interação entre eles. Caso este ambiente seja caracterizado por violências, aumenta-se a probabilidade de ocorrerem conflitos agressivos e atos que envolvam transgressões legais (BECKER; KASSOUF, 2016).

Resultados semelhantes foram encontrados por Tavares e Pietrobom (2016) e Becker e Kassouf (2016), sendo que estes últimos observaram também associação positiva entre o comportamento violento dos alunos, tráfico de drogas e atuaçáo de gangues no entorno das instituiçóes.

A sociologia do crime considera o gênero como uma variável consistente no fenômeno criminal com os homens praticando mais crimes e as mulheres sendo mais vítimas (MACHADO, 2008), entretanto esse cenário pode ser diferente em casos de crimes mais violentos. Os resultados apresentados neste estudo se alinham aos conceitos sociológicos pois os homens representaram o maior percentual na autoria dos crimes e as mulheres o maior percentual de vítimas.

Os resultados também demonstraram que os homens são as maiores vítimas de crimes violentos no entorno das escolas tais como roubos, estupros e homicídios. Destaca-se o fato dos homens representarem um percentual maior entre as vítimas em casos de estupros de vulneráveis o que difere dos resultados de outros trabalhos (CERQUEIRA; COELHO, 2014; SOUTO et al, 2017). Uma hipótese para esse resultado é o fato de estar sendo analisado somente o entorno das escolas e não os crimes em uma maior extensão territorial.

Os resultados confirmam os achados de Bowen e Bowen (1999) que demonstraram serem os homens mais expostos a atos de violência no entorno das escolas e o fato de serem negros tende a acirrar ainda mais essa exposição. O Fórum Brasileiro de Segurança Pública (FBSP) analisando 5.896 boletins de ocorrência aponta que $99,3 \%$ das mortes decorrentes de intervençóes policiais são de pessoas do sexo masculino e 0,7 do sexo feminino (FBSP, 2017), esses dados demonstram maior envolvimento dos homens em atos maior periculosidade.

As mulheres são as maiores vítimas da violência no entorno das escolas, os dados apresentados sáo compatíveis com a existência de opressão feminina no entorno das unidades, ou seja, os homens 
como autores de crimes possuem como alvos principais as mulheres. Esse tipo de crime tem merecido destaque nos estudos que envolvem a violência, no período entre 2006 e 2016 ocorreu um aumento de 6,4\% no número de homicídios envolvendo mulheres (IPEA, 2018). Embora os resultados aqui descritos captem apenas o entorno das escolas eles refletem a situação de periculosidade a qual estão submetidas as mulheres brasileiras.

Quando se analisa o aspecto social de um modo geral verifica-se que pessoas pardas e pretas tem, mais frequentemente, NSE mais baixo. $\mathrm{O}$ contexto que envolve a violência também reflete essa situação, os resultados captados pelos boletins de ocorrência demonstraram que as pessoas pardas se encontram mais envolvidas nos crimes seja como autores ou vítimas e se considerarmos os negros (pardos e pretos) o percentual de envolvimento é ainda maior.

O Índice de Vulnerabilidade Juvenil $^{8}$ (IVJ), aponta que em Minas Gerais a chance de um jovem negro ser vítima de homicídio é 2,1 maior se comparado com o jovem de cor branca (BRASIL, 2017). Os resultados desse trabalho apontam que as pessoas negras se mostram mais envolvidas com a violência no entorno das escolas se comparado com os brancos o que corrobora os dados do IVJ.

Como os jovens estão mais expostos aos condicionamentos dos grupos sociais primários há uma tendência em conside- rarem como referência o comportamento de pessoas que os circundam, se estes indivíduos forem violentos há probabilidade de os jovens também apresentarem tal comportamento (BECKER; KASSOUF, 2016).

Os dados demonstram que dois terços dos envolvidos em crimes no entorno das escolas são pessoas que possuem idades entre 11 e 17 anos. Esse resultado era esperado uma vez que o estudo analisa o entorno das escolas e há maior possibilidade de pessoas nessa faixa etária frequentarem esse ambiente. Como essas pessoas envolvidas se encontram em idade escolar deve-se observar que frequentar unidades escolares que estão inseridas em ambientes violentos tende a aumentar o insucesso e diminuir as chances de conclusão no Ensino Médio (TEIXEIRA; KASSOUF, 2015).

Os resultados demonstrados na regressão confirmam parcialmente a hipótese apresentada com exceção das características relacionadas à formaçáo docente e a complexidade das escolas, para as quais foram encontradas associaçôes diferentes das esperadas com a violência no entorno das escolas.

Estudos já identificaram que o NSE no Brasil está fortemente associado às condiçóes de desigualdade social e educacional (ALVES; SOARES; XAVIER, 2014), os resultados encontrados acompanham a literatura ao apresentarem associaçáo positiva entre menor NSE das escolas e violên-

8 Índice de vulnerabilidade Juvenil à Violêncio é um indicador, desenvolvido pela Secretaria Nacional de Juventude em parcerio como FBSP agregando dados tais como frequência à escola, escolaridade, inserção no mercado de trabalho, mortalidade por homicídios e acidentes de trônsito. 
cia no entorno dessas unidades. Trabalhos de Teixeira e Kassouf (2015), Almeida e Betini (2015), Cerqueira et al. (2016) encontraram resultados semelhantes.

A Regularidade Docente é uma característica relevante uma vez que a presença constante do professor favorece a aprendizagem dos alunos (COUTO; SOARES, 2016), alguns trabalhos apontam relaçóes positivas entre frequentes situaçóes de desordem na escola e ociosidade dos alunos em decorrência da ausência de professores (SPOSITO, 2001; TEIXEIRA; KASSOUF, 2015).

Os resultados desse estudo sugerem que os docentes optam por não se fixarem em escolas que estão localizadas em áreas violentas gerando uma rotatividade maior nos quadros dessas instituiçóes. Resultados semelhantes foram encontrados nos estudos do Oliveira e Ferreira (2013), Ribeiro (2013) e Cerqueira et al. (2016).

Previamente à regressão foi realizado o teste Qui-Quadrado que permite verificar a associação de cada variável contextual com a variável resposta. Este teste mostrou associação positiva entre a baixa formação docente e a presença de crimes no entorno das instituiçóes. Contudo no modelo de regressão, onde se capta o efeito líquido de cada variável, a formaçáo docente tem um sinal negativo $(-0,26)$, ou seja, a associação mudou de direçáo.

Isso é consequência da associação entre o indicador de formaçáo docente com as outras variáveis. Uma possível explicação à associaçáo negativa, que precisa de análise com outros dados, é que as escolas menos complexas e de baixo NSE estão situadas em periferias, espaços socialmente mais degradados. Nesta situação, depois de consideradas as outras variáveis, é razoável supor que os docentes residam no entorno da escola. Sua familiaridade e conhecimento do local, o respeito que tem junto aos alunos permite uma maior influência contra a violência.

Tavares e Pietrobom (2016) analisando a Rede Estadual de São Paulo encontraram resultados semelhantes ao demonstrar ser positiva a relação entre maior qualificação dos docentes e a ocorrência de atos violentos contra pessoas, além de demonstrarem associação positiva entre maior experiência dos professores e ocorrências de crimes.

Esperava-se que as escolas com baixa complexidade estivessem associadas de forma negativa com a violência em seu entorno por apresentarem uma gestáo mais simplificada. Entretanto, os resultados demonstram o contrário, que um entorno violento está associado com escolas que possuem baixa complexidade, esse resultado é inverso ao encontrado por Cerqueira et al. (2016).

Uma explicação para esse resultado é o fato de que escolas que atendem menos alunos e possuem menos etapas estarem localizadas em regióes mais afastadas dos grandes centros e nesse caso poderem apresentar menores condiçóes de segurança e atenção por parte das autoridades, mas é uma situação que também precisa ser investigada em outros estudos.

A baixa infraestrutura das escolas está associada de forma positiva com a violência em seu entorno, resultados semelhantes foram encontrados por Tavares e Pietrobom (2016). Resultados do trabalho de Becker e Kassouf (2016) demonstraram 
ser positivas as associaçóes entre violência e casos de depredação escolar e crimes contra o patrimônio. As escolas devem possuir uma estrutura mais adequada de modo a oferecer mais segurança aos alunos e docentes e proporcionar condiçóes mais adequadas para o processo de ensino aprendizagem (SOARES NETO et al., 2013).

\section{Conclusão}

A principal contribuição desse trabalho foi utilizar dados de boletins de ocorrência para analisar a associação entre violência no entorno das escolas e o contexto escolar. Os resultados encontrados se mostraram alinhados com a literatura existente, entretanto esse estudo apresentou algumas limitaçóes que estimulam outros trabalhos.

Os dados utilizados provem de registros administrativos e não permitiram verificar a causalidade entre as características das escolas e o entorno violento. Entretanto, são os únicos disponíveis e sua utilização precisa ser mais frequente em outros estudos. Sugere-se que o agente público, ao lavrar as ocorrências em que o local do fato seja uma escola, aponte no registro do boletim se os envolvidos se tratam de alunos ou pessoas do quadro das escolas, o que seria de grande contribuição para as pesquisas sobre atos de violência dentro e no entorno das escolas.

As características formação docente e complexidade apresentaram resultados contrários à hipótese da pesquisa e necessitam de mais evidências empíricas que demonstrem a sua relaçáo com a violência no entorno das escolas.

Os resultados aqui descritos demonstraram que a baixa regularidade e a baixa infraestrutura estáo associadas de modo positivo com a violência, essas características sáo passíveis de intervençáo a partir de políticas públicas e os dados aqui apresentados podem contribuir para melhoria dessas condiçóes como menor rotatividade dos professores e melhor infraestrutura das escolas inseridas em regióes mais violentas. Condiçóes essas que podem contribuir para diminuir a influência do entorno violento na vida dos alunos.

\section{Referências Bibliográficas}

ABRAMOVAY, Miriam; RUA, Maria das Graças. Violências nas escolas. Brasilia: UNESCO, 2002.

ALMEIDA, Luana Costa; BEIINI, Geraldo Antônio. Investigação sobre a escola e seu entorno: estudo bibliográfico de produções nacionais. Revista de Educação Pública. Cuiabá, v. 24, n. 55, jan./abr. 2015, pp. 33-56.

AMMERMÜLLER, Andreas. Violence in european schools: victimization and consequences, Discussion Paper 07-004, Centre for European Economic Research - ZEW, Mannheim. 2007, pp. 1-40.

AKIBA, MotokO; LE TENDRE, Gerald; BAKER, David P.; GOESLING, Brian. Student victimization: National and school system effects on school violence in 37 nations, American Educational Research Journal 39(4), 2002, pp. 829-853.

ALVES, Maria Teresa Gonzaga; SOARES, José Francisco. Contexto escolar e indicadores educacionais: condições desiguais para a efetivação de uma política de avaliação educacional. Educação e Pesquisa. São Paulo, v. 39, n. 1, jan./mar. 2013, pp. 177-194. 
. Índice Sócioeconômico das Escolas de Educa-

ção Básica Brasileiras. Ensaio: aval. pol. públ. Educ., Rio de Janeiro, v.22, n. 84, jul./set. 2014, pp. 671-704.

BECKER, Kalinca Léia; KASSOUF, Ana Lúcia. Violência nas escolas públicas brasileiras: uma análise da relação entre o comportamento agressivo dos alunos e o ambiente escolar. Nova Economia, v.26, n.2, Belo Horizonte mai./ aug. 2016.

BOROFSKY, Larissa; KELLERMAN, Ilana; BAUCOM, Brian; OLIVER, Pamella H; MARGOLIN, Gayla. Community Violence Exposure and Adolescents' School Engagement and Academic Achievement Over Time. Psychol Violence. 2013 Oct 1;3(4), pp.381-395.

BOWEN, Natasha. K.; BOWEN, Gary. L. Effects of Crime and Violence in Neighborhoods and Schools on the School Behavior and Performance of Adolescents. Journal of Adolescent Research, v. 14, n. 3, 1999, pp.319342.

BRASIL. Constituição da República Federativa do Brasil. Brasília, 1988.

Índice de Vulnerabilidade Juvenil à Vio-

lência 2017: desigualdade racial, municípios com mais de 100 mil habitantes. São Paulo: Fórum Brasileiro de Segurança Pública, 2017.87 p.

CERQUEIRA Daniel; COELHO, Danilo de Santa Cruz. Nota Técnica nº 11: Estupro no Brasil: uma radiografia segundo os dados da Saúde. Brasília: Instituto de Pesquisa Econômica Aplicada; 2014.

CERQUEIRA, Daniel; RANIERE, Mariana; GUEDES, Erivelton; COSTA, Joana Simões; BATISTA, Filipe; NICOLATO, Patricia. Indicadores Multidimensionais de Educação e Homicídios nos Territórios Focalizados pelo Pacto Nacional pela Redução de Homicídios. Nota técnica 18, Brasilia, 2016.

COUTO, ANDRE AUGUSTO, SOARES, JOSÉ FRANCISCO. AS relações entre Contexto Escolar e Qualidade da Edu- cação: evidências da Rede Estadual de Minas Gerais. Anais do IV Congresso Nacional de Avaliação em Educação: IV CONAVE. Bauru: CECEMCA/UNESP, 2016.

DEBARBIEUX, Eric. La violence à l'École: approaches européenes. Revue Française de Pédagogie, n. 123, mai./jun., 1998.

DEMARIS, Alfred. A Tutorial in Logistic Regression. Journal of Marriage and the Family, v.57, n.4, 1995, pp. 956-968.

FRANCO, Creso; ORTIGÃO, Isabel; ALBERNAZ, Ângela; BONAMINO, Alicia; AGUIAR, Glauco; ALVES, Fátima; SÁTYRO, Natália; Qualidade e equidade em educação: reconsiderando o significado de "fatores intra-escolares". Ensaio: Avaliação e Políticas Públicas em Educação, Rio de Janeiro, v. 15, n. 55, 2007, pp. 277-298,

FÓRUM BRASILEIRO DE SEGURANÇA PÚBLICA. Anuário Brasileiro de Segurança Pública 2017. São Paulo, 2017.

GAMA, Victor A., SCORZAFAVE, Luiz Guilherme. Os efeitos da criminalidade sobre a proficiência escolar no ensino fundamental no município de São Paulo. Pesquisa e Planejamento Econômico, v.43, n.3, 2013, pp. 447-77.

GROGGER, Jeffrey. Local violence and educational attainment. Journal of Human Resources, v. 32, n.4, 1997, pp.659-682.

HURT, Hallam; MALMUD, Elsa; BRODSKY, Nancy L.; GIANNEITA, Joan. Exposure to violence: psychological and academic correlates in child witnesses. Arch. Pediatr. Adolesc. Med. 2001 Dec;155(12), pp.1351-6.

INSTITUTO DE PESQUISA ECONÔMICA APLICADA. Atlas da Violência 2018. Rio de Janeiro, 2018.

INSTITUTO NACIONAL DE ESTUDOS E PESQUISAS EDUCACIONAIS ANÍSIO TEIXEIRA. Indicadores Educacionais. Disponível em: <http://portal.inep.gov.br/indicadores-educacionais>. Acesso em: 18 de maio de 2018.

KARINO, Camila Akemi; LAROS, Jacob Arie. Estudos bra- 
sileiros sobre Eficácia Escolar: uma revisão de literatura. Revista Examen, Brasilia, v. 1, n. 1, jul./dez 2017, pp. 95-126.

MACHADO, Helena. Manual de Sociologia do Crime. Porto: Afrontamento, 2008.

MINAS GERAIS. Registro de Eventos de Defesa Social. Belo Horizonte, MG, 2015.

OLIVEIRA, Victor Rodrigues; FERREIRA, Diego. Violência e desempenho dos alunos nas escolas brasileiras: uma análise a partir do SAEB 2011. Revista Econômica, Niterói, v.15, n. 1, jun. 2013, pp. 84-114.

RATNER, Hilary Horn; CHIODO, Lisa; COVINGTON, Chandice; SOKOL, Robert J.; AGER, Joel; DELANEY-BLACK, Virginia. Violence exposure, IQ, academic performance, and children's perception of safety: Evidence of protective effects. Merrill-Palmer Quarterly, 52, 2006. pp. 264-287.

RIBEIRO, Eduardo; Impactos educacionais nas Unidades de Polícia Pacificadora: Explorando os efeitos sobre os fluxos docentes. Revista Intratextos, v. 4, n.1, 2013, pp. 27-52.

RUOTII, Caren. Violência em meio escolar: fatos e representações na produção da realidade. Educação e Pesquisa, São Paulo, v.36, n.1, jan./abr. 2010, pp. 339-355.

SEVERNINI, Edson; FIRPO, Sérgio Pinheiro. The relationship between school violence and student proficiency. Texto para discussão nº 236 - EESP/FGV, 2009.

SILVA, Joyce Mary Adam; SALLES, Leila Maria Ferreira. Jovens, violência e escola: um desafio contemporâneo [online]. São Paulo: Editora UNESP; São Paulo: Cultura Acadêmica, 2010. 182 p.
SOARES NETO, Joaquim José; JESUS, Girlene Ribeiro de; KARINO, Camila Akemi; ANDRADE, Dalton Francisco de. Uma escala para medir a infraestrutura escolar. Estudos em Avaliação Educacional, v. 24, n. 54, jan./abr. 2013, ppp. 78-99.

SOUTO, Rayone Moreira Costa Veloso; PORTO, Denise Lopes; PINTO, Isabella Vitral; VIDOTII, Carlos Cezar Flores; BARUFALDI, Laura Augusta; FREITAS, Mariana Gonçalves de; SILVA, Marta Maria Alves da; LIMA, Cheila Marina de. Estupro e gravidez de meninas de até 13 anos no Brasil: características e implicações na saúde gestacional, parto e nascimento. Ciência \& Saúde Coletiva, v. 22, ก.9, 2017, pp.2909-2918.

SPOSITO, Marilia Pontes. Um breve balanço da pesquisa sobre violência escolar no Brasil. Educação e Pesquisa. v. 27, n.1, jan./jun. 2001, pp. 87-103.

TAVARES, Priscilla Albuquerque; PIETROBOM, Francine Carvalho. Fatores associados à violência escolar: evidências para o Estado de São Paulo. Estudos Econômicos. v.46, n.2, 2016, pp.471 - 498.

TEIXIERA, Evandro Camargos; KASSOUF, Ana Lúcia. Impacto da violência nas escolas paulistas sobre o desempenho acadêmico dos alunos. Economia Aplicada, v. 19, п. 2, 2015, pp. 221-240.

WAISELFISZ, Julio Jacobo. Mapa da violência 2015: adolescentes de 16 e 17 anos do Brasil. Faculdade Latino-Americana de Ciências Sociais (FLACSO), 2015, pp. 1-72.

ZALUAR, Alba, LEAL, Maria Cristina. Violência extra e intramuros. Revista Brasileira de Ciências Sociais, v. 16, ก. 45, fev. 2001, pp. 145-164. 


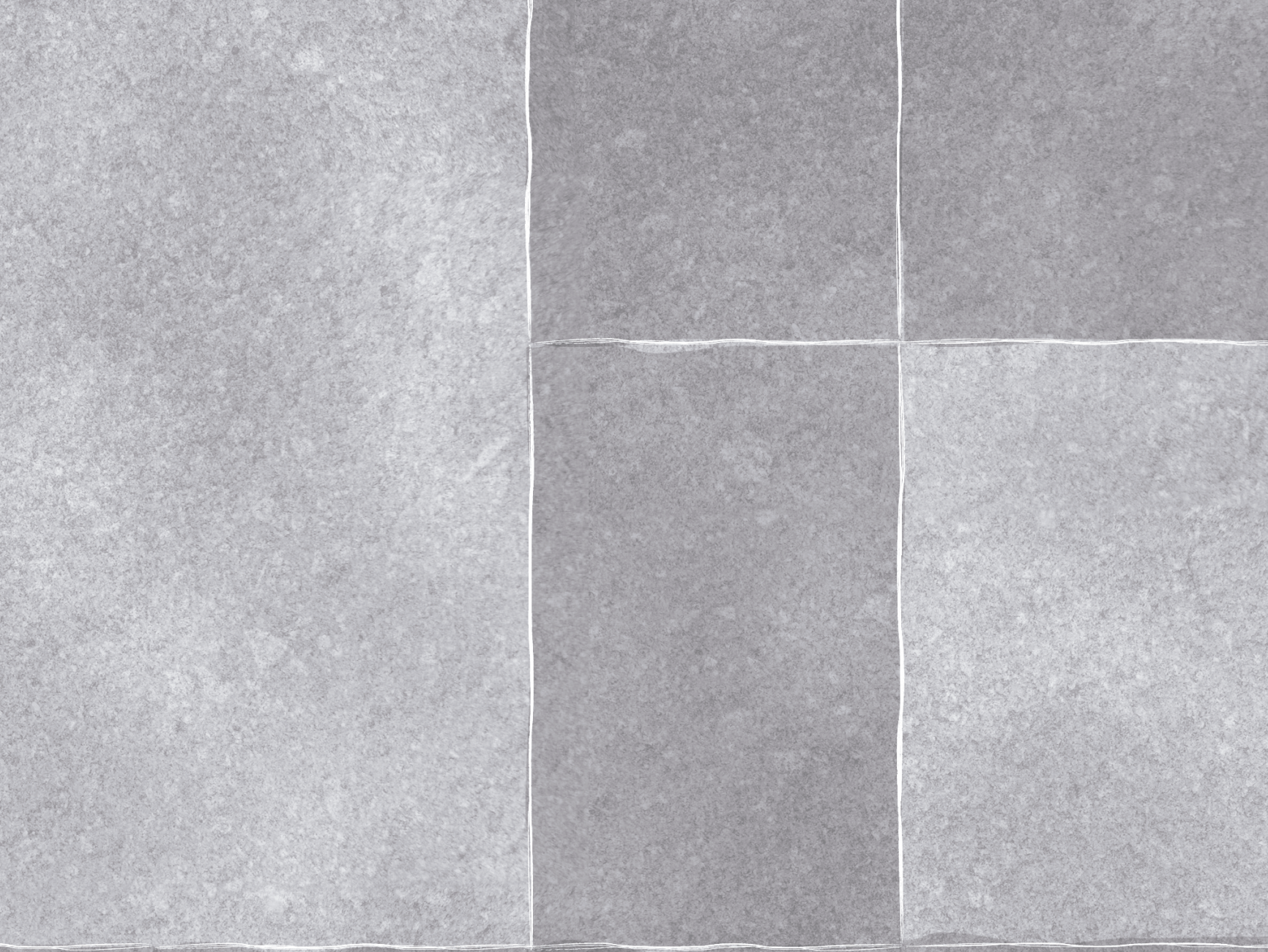

